\title{
Surface Topography of Inconel 718 Alloy in Finishing WEDM
}

\author{
Jarosław Buk ${ }^{1}$
}

1 Faculty of Mechanical Engineering and Aeronautics, Rzeszów University of Technology, ul. Powstańców Warszawy 12, 35-959 Rzeszów, Poland

E-mail: jbuk@prz.edu.pl

\begin{abstract}
The properties of Iconel 718 determine its application for parts operating in extremely tough conditions. The difficulties when machining nickel-based superalloys allowed in recent years for researching other machining methods. One of the proposed methods is Wire Electrical Discharge Machining (WEDM). It becomes possible to minimize or eliminate such problems associated with electrical discharge machining as microcracks, forming of a white layer, or high surface roughness. One way to avoid these issues is to apply finishing machining. The literature indicates that the peak current is the main parameter responsible for shaping the machined surface in finishing WEDM. Furthermore, few works focus on the electrode's infeed, in particular there are not many papers regarding the influence of the infeed on the machined surface parameters. Therefore, the paper aims to investigate on the influence of the peak current and infeed during finishing WEDM on the surface properties of Inconel 718. The paper presents measurements of selected surface topography parameters and Abbot Firestone curves (AFC). The presented plots allowed to determine the ranges of the process parameters for which the lowest surface roughness values were achieved. Cross-sections were performed to measure the thickness of a white layer. Nanohardness $\mathrm{HV}_{0,01}$ measured by Berkovich tip was recorded to determine the size of a heat affected zone (HAZ). The correlation between the peak current $I_{c}$ and the infeed $z$ regarding the machined surface quality was presented.
\end{abstract}

Keywords: WEDM, Inconel 718, surface topography, nanohardness, surface layer.

\section{INTRODUCTION}

In WEDM the tool is an electrode in the form of a wire. Usually, it is a brass wire of a small diameter $(0.2-0.25 \mathrm{~mm})$. The machining zone is submerged in a dielectric liquid, which the most often is distilled water. The removal of material occurs due to melting and evaporation as a result of electric discharges [1,2]. A characteristic feature of this type of machining is the removal of a significant volume of a workpiece in the form of a core as a result of the erosion of a small amount of material [3]. The advantage of WEDM is the ability to machine materials regardless of their hardness. The disadvantages include the occurrence of microcracks in the surface layer as well as the forming of the white layer [4,5]. WEDM can be divided into rough and finishing machining. Additional finishing passes result in less heat impact. This, in turn, leads to a reduction in the stresses in the surface layer. It can allow, in the case of materials of high hardness and strength, to prevent the occurrence of microcracks. Thus, new possibilities arise in the machining of difficult-tocut materials, such as HRSA superalloys, including nickel superalloys $[6,7]$. Adding to the above the ecological requirements, research on the new methods of machining difficult-to-cut materials is of great importance.

The development of technology in recent years allows for applying WEDM in the industrial sectors where it was previously impossible to use it. In the aviation, energy or automotive industries, difficult-to-cut materials are still shaped with the conventional machining methods. Due to the shape of the tools, their production and regeneration difficulties, those methods are expensive and time-consuming. Thus, alternative methods 
both in terms of roughing and finishing, are being sought. In WEDM, the tool is an electrode in the form of a wire, which makes the production of such a tool simple and more economical, and programming of new contours is quick, which positively affects the flexibility of the production, in comparison with other machining methods [8]. In the case of rough machining, electrical discharge machining allows for removing a significant volume of material, leaving a small allowance for traditional machining. High shape and dimensional accuracy as well as surface quality can be achieved in finishing machining. Thus, WEDM could be implemented to produce parts without the need for traditional machining [9]. A characteristic finishing parameter is the infeed $z$ of the wire electrode (Fig. 1).

The infeed $\mathrm{z}$ is the distance between the roughing path and the finishing path. Klocke at al. [9] researched the influence of power supplies in roughing and finishing machining (peak current $I_{c}=4 \mathrm{~A}$ ) on the surface roughness and machining efficiency of Inconel 718 alloy. The authors indicated the fact that the WEDM machine tool manufacturers provide the machining technology only for the materials such as steels, copper and aluminum alloys but there seems to be a lack of complete technology for the nickel-based alloys. Thus, there is a need of conducting research on roughing and finishing parameters for that type of alloys. Burek et al. [10] conducted research on the influence of electrical parameters of a power supply in finishing machining (peak current $I_{c}=3.5$ $28 \mathrm{~A}$ ) and the infeed in WEDM of fir tree slots on the surface quality and shape accuracy. The authors determined mathematical models of the surface roughness $R a$. In their research, among the tested parameters, the discharge energy proved

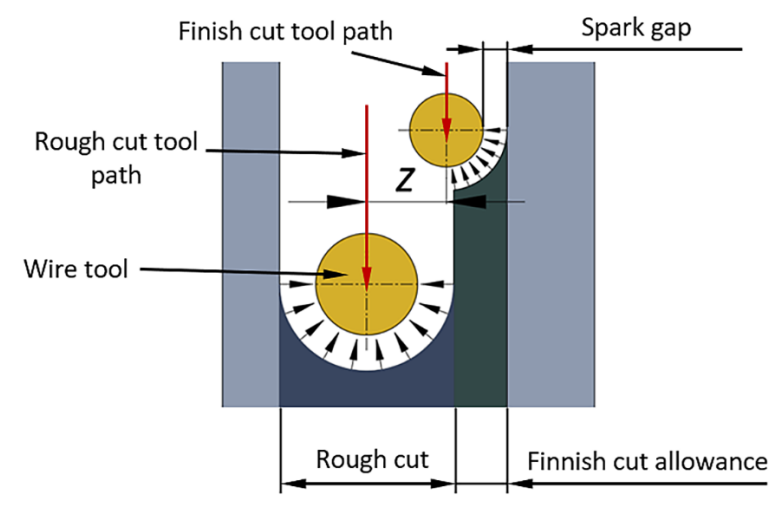

Fig. 1. Allowances for roughing and finishing machining [9] to have the greatest impact on the surface roughness $R a$. On the other hand, the influence of the pulse off time was negligible. The authors also indicate that the infeed of approximately $50 \mu \mathrm{m}$ can significantly improve the surface roughness $R a$. Liao et al. [11] studied the influence of the pulse on time, pulse off time, machining voltage, feed rate and infeed (from the range of $0-25 \mu \mathrm{m}$ ) on the surface quality after WEDM. The authors indicate a significant influence of the machining voltage, however the peak current was not considered. Newton et al. [12] proved that the discharge energy significantly influences the surface quality after WEDM. The authors proved as well that the peak current, pulse on time and discharge energy significantly impact the thickness of the surface layer. Aspinwall et al. [13] investigated the influence of the thickness of the removed material in four finishing passes on the surface roughness $R a$ and the thickness of the white layer using ultra high frequency/short duration pulses generators. In the subsequent passes the thickness of removed layers was as follows: 74, 18, 11 and $2 \mu \mathrm{m}$. The authors indicate that in many of the finishing passes the thickness of the white layer was almost completely reduced and the achieved surface roughness was equal to $R a=0.21 \mu \mathrm{m}$. Li et al. [14] researched the influence of the discharge energy on the surface quality after three finishing passes. The authors indicate that as the discharge energy decreased, the surface roughness $R a$ decreased as well. The authors also tested the microhardness of the surface layer. They proved that the hardness of the white layer is approximately $50 \%$ lower than that of the core material, whereas the heat affected zone (HAZ) is approximately $10-20 \mu \mathrm{m}$ thick into the bulk material.

Moreover, Hasçalýk et al. [15] indicate that the thermal nature of electrical discharge machining determines that important issues of this kind of machining are the surface topography, surface layer, including the heat-affected zone and the stresses causing microcracks. Han et al. [16] verified the effect of the current peak and discharge time on the surface quality using temperature analysis. The authors indicate that high discharge currents with short discharge times remove material in gaseous form. Low current values with long discharge times remove material by melting. The authors indicate that the same roughness can be obtained for different discharge times with almost the same discharge current, but with a diametrically different condition of the surface layer. 
Therefore, the authors conclude that during finishing machining, where low surface roughness is important, only short discharge times can be used. Huang et al. [6], indicate that the important process parameters influencing the effects of finishing machining are: the discharge time $t_{o n}$ and electrode infeed $z$. The low infeed value allows for overlapping of the machining marks after roughing and finishing. Thus, it allows to remove the peaks left on surface after rough machining. This, in turn, lowers the surface roughness compared to the complete removal in finishing with higher infeed. However, it should be noted that in the first case, microcracks may appear on parts of the surface after roughing. The authors indicate that the thickness of the layer removed in the finishing machining should be 10 times the surface roughness (minimum $30 \mu \mathrm{m}$ ). Huang et al. [17] verified the influence of WEDM machining parameters of YG15 steel on the Ra surface roughness in both roughing and finishing machining (Fig. 2). They found that the surface roughness $R a$ in roughing is mainly dependent on the discharge time. In finishing, on the other hand, it depends on the intensity of the discharge current peak, the feed rate and, to a lesser extent, dielectric flow rate into the working gap.

Klocke et al. [18] investigated the use of Topas plus X (TPX) and AGN3C - (AG) coated electrodes in comparison to a standard brass electrode. The authors found that the use of coated electrodes increases the surface roughness $R a$ in relation to the surface machined with a brass electrode. The authors investigated the influence of the infeed on the electrode deflection caused by the electrostatic force and the detracting force. The infeeds in the range of -4 to $16 \mu \mathrm{m}$ were tested. The results indicate that with the increase of the infeed, the forces become similar and the deflection of the electrode is reduced. This results in an even material removal form the entire machined surface. On the other hand, Li et al. [19] used the $\mathrm{Cu}$-Sic composite electrode, obtaining $17.1 \%$ lower $R a$ roughness compared to the standard brass electrode at the current peak of $14.2 \mathrm{~A}$, and $16.5 \%$ lower $R a$ at the current peak of $25.6 \mathrm{~A}$. Okada et al. [20] analyzed the influence of electrode surface roughness on the effects of WEDM machining. The studies have shown that the use of electrodes with increased surface roughness does not change the roughness $R a$ of the machined surface, but increases the machining efficiency, probably due to the increase in the frequency of discharges. Antar et al. [21] noted that nickel and titanium alloys show little susceptibility to microcracks and the presence of a white layer. The authors applied a finishing machining to the Udimet 720 nickel-based alloy reducing the Sa surface roughness from $3.3 \mu \mathrm{m}$ after roughing to 0.5 $\mu \mathrm{m}$ after the fourth finishing pass. The white layer thickness was reduced from $\leq 10 \mu \mathrm{m}$ after roughing to $0.5 \mu \mathrm{m}$ after the fourth finishing pass. The authors indicated that such an effect was due to the reduction in energy in each subsequent finishing pass. Antar et al. [22] proposed the use of a "minimum damage EDM pulse generator" and coated electrodes with a copper core and brass coating and a copper core and a double zinc coating. The authors state that it is possible to obtain (after two finishing passes) a surface roughness of $R a=0.6$ $\mu \mathrm{m}$ and a white layer with a thickness close to zero. Ayesta et al. [23] compared the strength of an Inconel 718 sample made by grinding and by the WEDM method. The authors note that most of the researches on the results of EDM present the results of cutting steel, which would be due to the fact that EDM is often used in the machaning of dies. The authors indicate that the surface

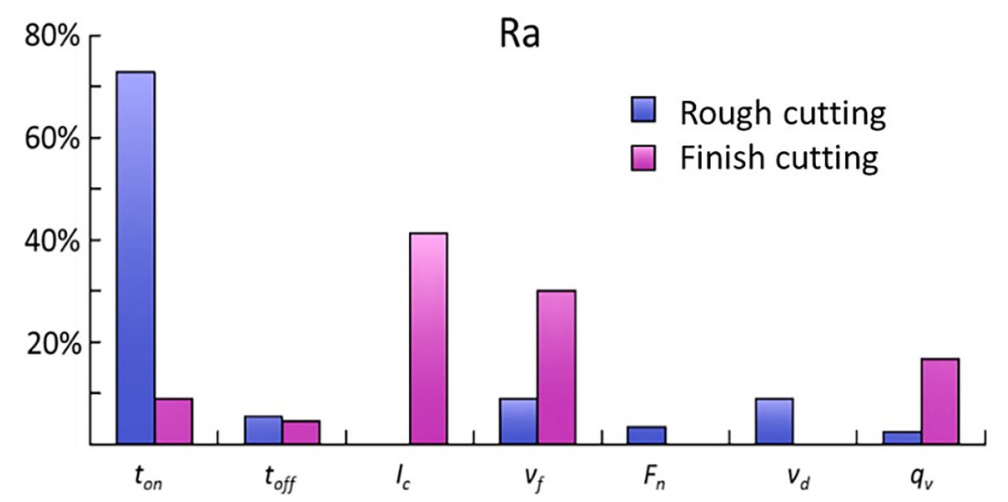

Fig. 2. Comparison chart of WEDM parameters effects on $R a$ between rough and finish machining [17] 
Table 1. Chemical composition of Inconel 718 [33]

\begin{tabular}{|c|c|c|c|c|c|c|c|c|c|c|c|c|c|c|}
\hline \multirow{2}{*}{ Alloy } & \multicolumn{10}{|c|}{ Chemical composition, wt.\% } \\
\cline { 2 - 24 } & $\mathrm{C}$ & $\mathrm{Si}$ & $\mathrm{Mn}$ & $\mathrm{Cr}$ & $\mathrm{Mo}$ & $\mathrm{Ni}$ & $\mathrm{Co}$ & $\mathrm{Ti}$ & $\mathrm{Al}$ & $\mathrm{Nb}+\mathrm{T}$ & $\mathrm{P}$ & $\mathrm{S}$ & $\mathrm{Fe}$ & $\mathrm{Cu}$ \\
\hline Inconel & $\mathrm{Max}$ & $\mathrm{Max}$ & $\mathrm{Max}$ & $17.0-$ & $2.8-$ & $50.0-$ & 0.04 & $0.65-$ & $0.2-$ & $4.75-$ & $\mathrm{Max}$ & $\mathrm{Max}$ & 18.5 & $\mathrm{Max}$ \\
718 & 0.08 & 0.35 & 0.35 & 21.0 & 3.3 & 55.0 & & 1.15 & 0.8 & 5.5 & 0.015 & 0.015 & 0.3 \\
\hline
\end{tabular}

roughness after WEDM machining with two finishing passes was $R a=0.58 \mu \mathrm{m}$ and was comparable to the surface roughness obtained in the grinding process $R a=0.53 \mu \mathrm{m}$. The heat affected zone in both methods was similar. After grinding, its thickness was approximately $4 \mu \mathrm{m}$, and after WEDM it was approximately $2.7 \mu \mathrm{m}$. Newton et al. [24] analyzed the impact of discharge energy in WEDM roughing on the formation of a white layer. The authors state that the current peak and the discharge time influence the thickness of the white layer to the greatest extent. The diameter of the electrode and the time between discharges had less effect. In addition, the discharge energy significantly influenced the surface roughness. Scott e al. [25] proposed a model for the selection of optimal parameters in order to increase the machining efficiency and obtain the best surface quality in rough machining of steel. As a result, the authors conclude that the discharge peak current, discharge time and frequency of discharges have the greatest influence on both factors. Arshad et al [26] proposed the use of distilled water and kerosene as dielectric during EDM. Distilled water resulted in better dielectric flow and material removal rate in the gap but lower surface roughness was obtained with kerosene. Imran et al [27] compared distilled water and paraffin oil as dielectric liquid. Distilled water made it possible to obtain a white layer of a smaller thickness compared to paraffin oil with the same machining parameters. Paraffin oil as a dielectric resulted in higher surface roughness compared to distilled water.

Previous studies focused mainly on the roughing machining of Inconel 718. The possibilities of using different types of electrodes and dielectrics were investigated. Much research has been focused on the influence of the discharge energy on the quality of the machined surface and machining efficiency. Few works focus on finishing WEDM, therefore the infeed parameter has not been thoroughly examined yet, especially in terms of the superalloys surface quality. Determining the correct range of infeed $z$ requires finding its maximum and minimum values. The maximum value should enable to machine without short circuits and without breaking the electrode. It is more difficult to determine the minimum value, which allows to completely remove any unevenness after roughing machining. In addition, the literature indicates that peak current and feed rate are important parameters influencing the surface quality after WEDM finishing. However, the feed rate is significantly adjusted by the control system of industrial machine tools, therefore the following paper aims to present the results of research on the influence of the electrode infeed and peak current on the surface quality after finishing machining of Inconel 718 alloy.

\section{MATERIALS AND METHODS}

The workpiece was a cuboid with base sides equal to $10 \mathrm{~mm}$ and a height of $30 \mathrm{~mm}$ made of Inconel 718 alloy. This alloy belongs to the group of nickel-based heat resistant super alloys (HRSA). Due to its high strength, high temperature creep resistance or oxidation and corrosion resistance, it has been used for parts that undergo high loads and high temperatures [28-31]. Inconel 718 is widely used for turbine discs, blades, combustion chambers and gas turbines in the energy and aviation industries [32]. The chemical composition of Inconel 718 is presented in Table 1.

The test stand was built based on the Mitsubishi FA10S wire electrical discharge machine tool equipped with the Mitsubishi W31 Advance control system. The machine tool was powered by a regenerative pulse transistor system. The control system of the machine allows programming using parameter notches. The tool adopted for the test was a wire brass electrode with a diameter of $0.25 \mathrm{~mm}$ and a tensile strength of $900 \mathrm{~N} / \mathrm{mm}^{2}$. The type of electrode is commonly used in the machine industry for both rough and finishing machining.

Rough machining had been made in the same WEDM process, right before the finishing pass was made. It was conducted with parameters set for cutting steel, according to the recommendations of the machine tool manufacturer, modifying 
Table 2. Values of set constant parameters for the machining

\begin{tabular}{|l|c|}
\hline \multicolumn{1}{|c|}{ Technological Parameter } & Value \\
\hline Mean gap voltage $U_{c^{\prime}}, \mathrm{V}$ & $\sim 27$ \\
\hline Pulse off-time $t_{\text {off }}, \mu \mathrm{s}$ & $\sim 24$ \\
\hline Wire running speed $v_{d}$, notch & 12 \\
\hline Wire tension $F_{n}, \mathrm{~N}$ & 19 \\
\hline Wire feedrate $v_{f}, \mathrm{~mm} / \mathrm{min}$ & 3.3 \\
\hline Dielectric flow rate $q_{\mathrm{vg}}, \mathrm{l} / \mathrm{min}$ & 1.4 \\
\hline
\end{tabular}

them according to the research in the works [34] and achieving the lowest surface roughness. Table 2 presents the constant machining parameters adopted for the experimental tests.

In the initial stage of the experimental tests, machining tests were performed, allowing to determine the ranges of the tested parameters: peak current $I_{c}$ and infeed $z$, for which stable machining was possible. The HP and MP (machine tool manufacturer's notations) power supplies, intended for finishing machining, were used in the tests. The HP generator allows for a wide range of tested $I_{c}$ parameter. The MP generator provides a low range of the tested $I_{c}$ parameter. The maximum and minimum value of the peak current $I_{c}$ was determined for both power supplies, which allowed for machining without breaking the electrode. The minimum and maximum value of the infeed $z$ was determined based on previous research and literature [35]. The values of the ranges of the tested parameters are presented in Table 3.

The determined ranges of parameters allowed for developing the design of experiment presented in Table 4.

The measurement of voltage and current was performed with the use of the Rigol RP1300H probe with a measuring range of $400 \mathrm{~V}$, as well as the Pearson probe with a sensitivity of $0.1 \mathrm{~V} / \mathrm{A}$. The signals from the probes were recorded with a Rigol DS1074Z oscilloscope with a sampling rate of $100 \mathrm{MHz}$ and a recording time of $600 \mu \mathrm{s}$. The data was saved in flash memory and analyzed using a PC.

Table 3. Available notches for tested parameters

\begin{tabular}{|l|c|}
\hline \multicolumn{1}{|c|}{ Technological Parameter } & Value \\
\hline $\begin{array}{l}\text { Peak current Ic, A } \\
\text { (for the HP power supply) }\end{array}$ & $\sim 15.5-73$ \\
\hline $\begin{array}{l}\text { Peak current Ic, A } \\
\text { (for the MP power supply) }\end{array}$ & $\sim 4-27$ \\
\hline Infeed z, $\mu \mathrm{m}$ & $30-70$ \\
\hline
\end{tabular}

Table 4. The design of experiment according to notches and corresponding to them tested parameters

\begin{tabular}{|c|c|c|}
\hline \multirow{2}{*}{$\begin{array}{c}\text { Number of } \\
\text { sample }\end{array}$} & $I_{c}$ & $z$ \\
\cline { 2 - 3 } & $\mathrm{A}$ & $\mu \mathrm{m}$ \\
\hline 1 & 4 & 30 \\
\hline 2 & 15.5 & 30 \\
\hline 3 & 27 & 30 \\
\hline 4 & 73 & 30 \\
\hline 5 & 4 & 50 \\
\hline 6 & 15.5 & 50 \\
\hline 7 & 27 & 50 \\
\hline 8 & 73 & 50 \\
\hline 9 & 4 & 70 \\
\hline 10 & 15.5 & 70 \\
\hline 11 & 27 & 70 \\
\hline 12 & 73 & 70 \\
\hline
\end{tabular}

Roughness parameters were measured with the Infinite Focus G4 Alicona focus variation microscope. The dimensions of the scanned areas were equal to $1.4302 \times 1.085 \mathrm{~mm}$ with a vertical resolution of $170 \mu \mathrm{m}$. The location of the scanned area was assumed in the middle of the workpiece height due to the concentration of impurities during machining.

The metallographic cross-sections were prepared as follows: the samples were mounted in epoxy resin. Then they were grinded and polished with a $\mathrm{SiO}_{2}$ suspension with a granulation of $0.25 \mu \mathrm{m}$. The samples prepared in this way were etched with $5 \%$ nital. The thickness of the white layer was measured on a Nikon EPIPHOT 300 light optical microscope (LOM).

Hardness was measured on a NHT 50-183 nanoindenter equipped with a Berkovich B-J 40 diamond tip. The measurement was conducted with a maximum load of $10 \mathrm{mN}$. The measurement consisted of recording the hardness after loading and removing the applied force. The curve of the force in respect of the Berkovich tip indentation depth was analyzed. The hardness was obtained based on a computer analysis of the indentation curve.

\section{RESULTS AND DISCUSSIONS}

The following sections present the measurements of selected surface roughness parameters, the measurement of the white layer/recast layer and the hardness measurements of the surface layer. 
a)

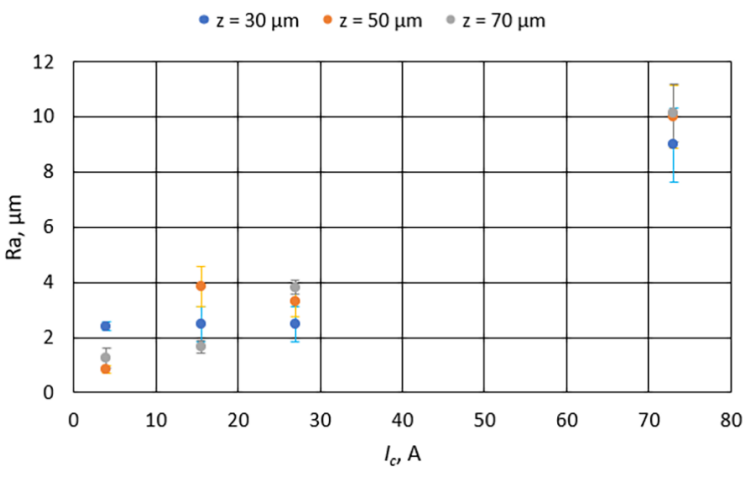

b)

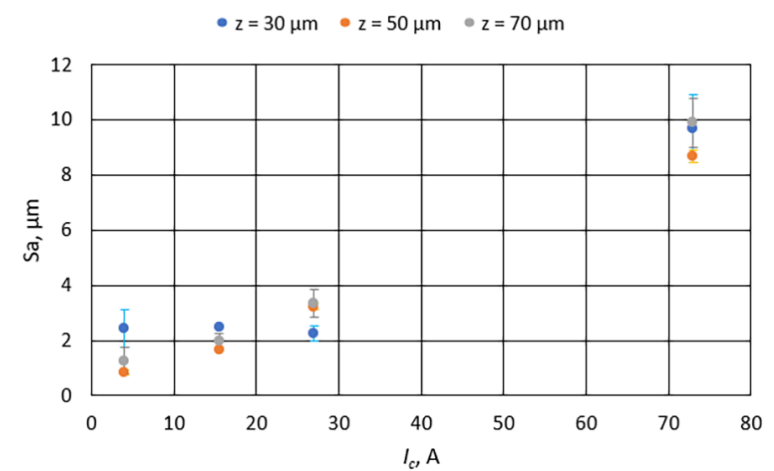

Fig. 3. Surface roughness parameters: a) $R a$, b) $S a$

\section{Surface roughness}

The analysis of the $S a$ and $S z$ parameters was extended to the $R a$ and $R z$ parameters as well, due to their common application in industry. Figure $3 \mathrm{a}$ presents the results of the $R a$ roughness measurements. The lowest value of the Ra parameter was obtained for the peak current $I_{c}=4 \mathrm{~A}$ and the infeed $z=50 \mu \mathrm{m}$. For higher values of the parameter $I_{c}=27-73 \mathrm{~A}$, the lowest infeed allowed to achieve the lowest surface roughness. One may assume that the higher value of the peak current $I_{c}$ allowed to obtain the discharge energy at a level sufficient to completely remove the surface after roughing machining, despite the small value of the infeed $z$. Figure $3 \mathrm{~b}$ presents the results of the Sa roughness measurements. The distribution of the $S a$ parameter is similar to that of the $R a$ parameter. Ishfaq et al. [36] also noted that the increase in surface quality of HSS form tool made by WEDM is obtained for lower electric parameters.

The lowest values of $R a$ and $S a$ parameters were achieved for $I_{c}=4 \mathrm{~A}$. For $I_{c}=4 \mathrm{~A}$, the infeed $\mathrm{z}$ proved to be too low to completely remove the surface after roughing and the obtained roughness was higher than in the case of higher infeeds $(z=$ $50 \mu \mathrm{m}$ and $70 \mu \mathrm{m}$ ). Too low infeed (Fig. 4 -infeed $z_{2}$ ) resulted in forces $F_{e}$ (electrostatic force) and $F_{d}$ (detracting force) acting on the electrode not being in equilibrium. If the force $F_{e}$ was higher, the electrode deflected and only the peaks were machined after the previous roughing machining. With the higher infeed value $(z=50 \mu \mathrm{m})$, the lowest surface roughness $R a$ and $S a$ was achieved.

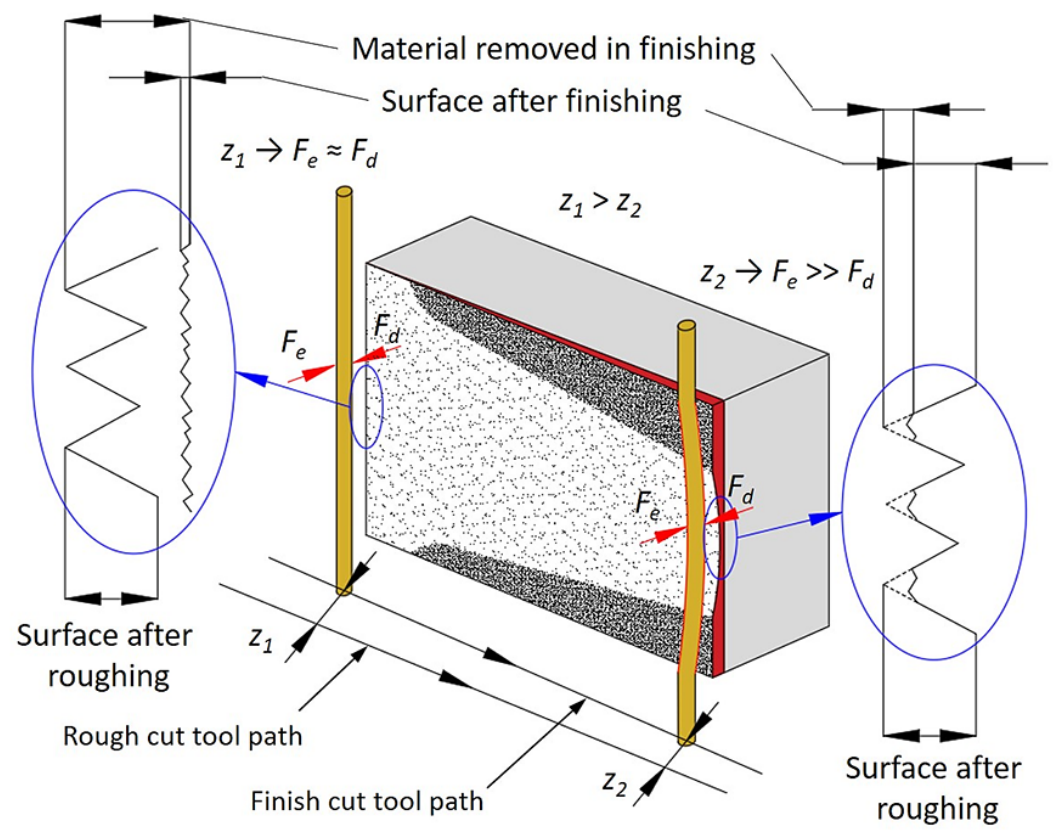

Fig. 4. Forces acting on the electrode during WEDM 
a)

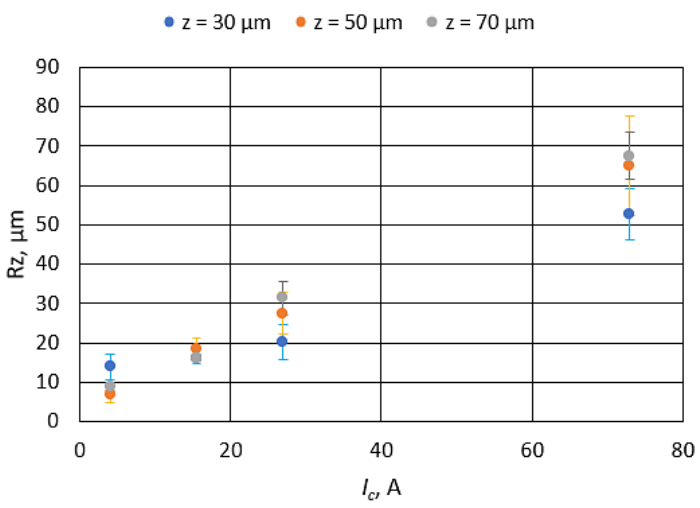

b)

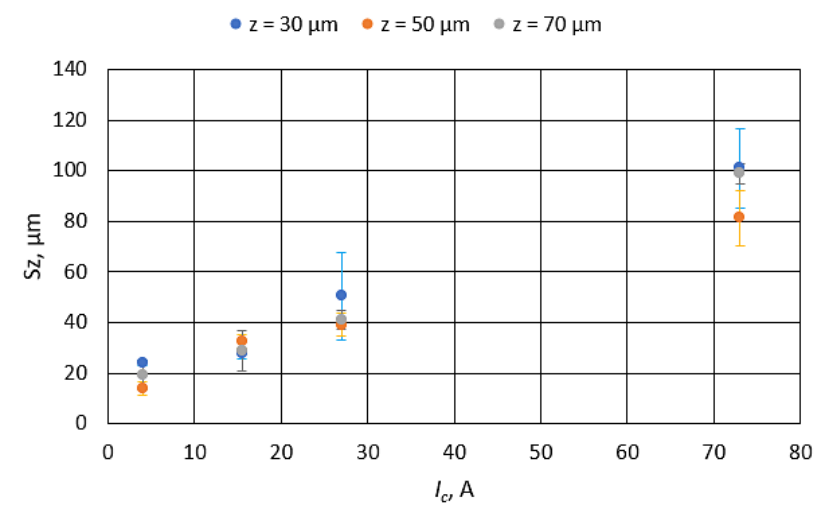

Fig. 5. Surface roughness parameters: a) $R z$, b) $S z$

This means that the $F_{d}$ force was high enough to balance the force $F_{e}$ (Fig. 4 -infeed $z_{l}$ ). It allowed to remove all the unevenness left after roughing machining. Klocke et al. [18] also indicated a significant influence of the infeed on values of the forces acting on the electrode during machining and on the $R a$ surface roughness.

Figure 5 presents the surface roughness parameter $R z$. The graph is similar to the $R a$ surface roughness. One can observe that the measurement dispersions increased with the increase of the peak current $I_{c}$.

The skewness Ssk parameter (Fig. 6) for the infeed $z=50 \mu \mathrm{m}$ and $z=70 \mu \mathrm{m}$ reached positive values. This indicates the presence of sharp peaks on the surface. For the infeed $z=30 \mu \mathrm{m}$ and low values of the peak current $I_{c}=4-15.5$ A, a negative value of the Ssk parameter was recorded. This, in turn, indicates that the peaks on the surface were rounded. Figure $3 b$ presents the results of $S z$ roughness measurements. As in the case of $R a$ and $S a$ parameters, the distribution of the $S z$ parameter is similar to the $R z$ roughness distribution. Only for the $I_{c}=73 \mathrm{~A}$, the difference between the $R z$ and $S z$ parameters was significant and amounted to approximately $40 \%$.

The results of the measurement of the kurtosis parameter $S k u$ are presented in Figure 7. For the lowest value of the peak current $I_{c}=4 \mathrm{~A}$ and all the infeeds $z$, the value of the parameter $S k u$ $=3.5-4$ was noted. This indicates that the distribution of surface ordinates is close to the normal distribution. This, in turn, means very even distribution of peaks and valleys. A similar value of the $S k u$ parameter was recorded only for the infeed $z$ $=30 \mu \mathrm{m}$ and $I_{c}=15.5 \mathrm{~A}$, as well as for $z=50 \mu \mathrm{m}$ and $I_{c}=73 \mathrm{~A}$. In other cases, the $S k u$ parameter significantly exceeded the value of $S k u=3$ (significant unevenness in the distribution of peaks and valleys on the surface).

Figure 8 presents the results of the measurement of the maximum peak height $S p$ parameter. With the increase of the peak current $I_{c}$, the height of the peaks increased, regardless of the infeed $z$. For the infeed $z=50 \mu \mathrm{m}$, a significantly lower increase in the $S p$ parameter value was observed

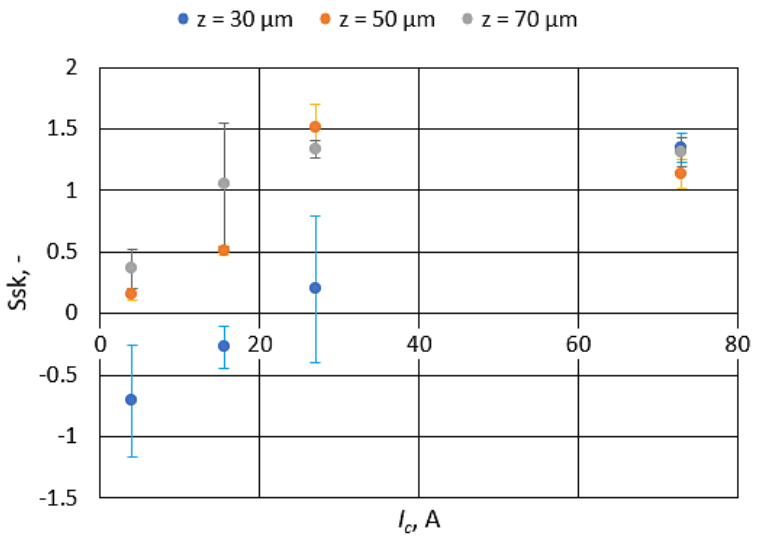

Fig. 6. Skewness parameter $S s k$

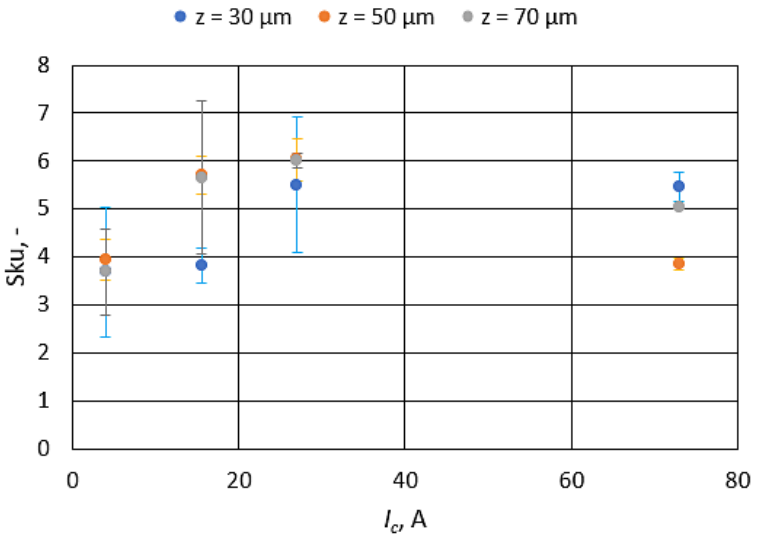

Fig. 7. Kurtosis parameter $S k u$ 


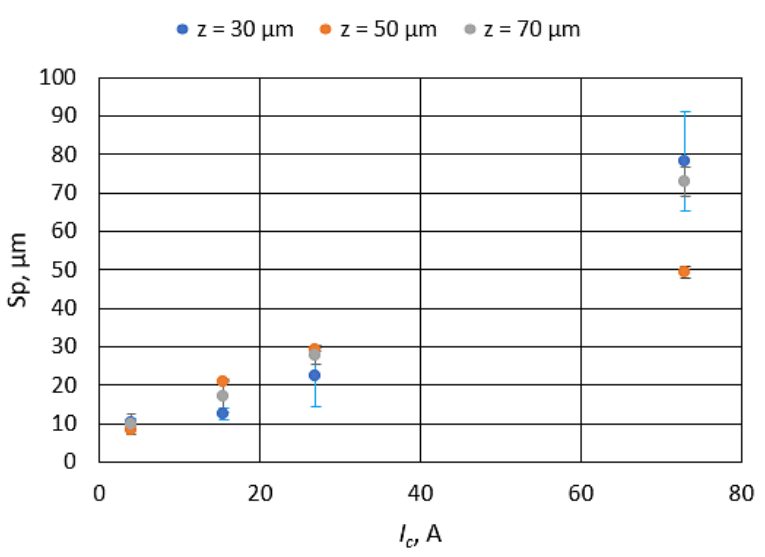

Fig. 8. Maximum peak height parameter $S p$

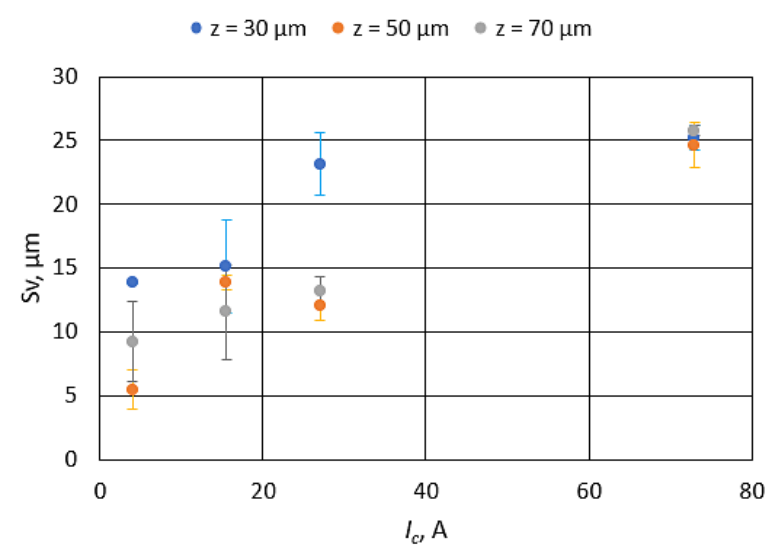

Fig. 9. Maximum height of surface parameter $S t$

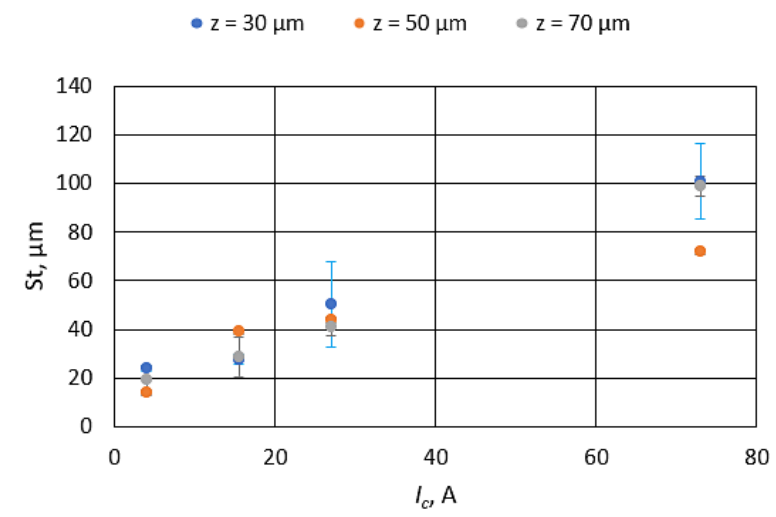

Fig. 10. Maximum pit height parameter $S v$

at the highest value of the peak current $I_{c}$ in comparison with the other infeeds. Similarly, the dispersion for the tests conducted with the infeed $z=$ $50 \mu m$ was significantly lower than for the infeed $z=30 \mu \mathrm{m}$ or $z=70 \mu \mathrm{m}$.

The distribution of the maximum height of surface $S t$ parameter (Fig. 9) is similar to the distribution of the $S p$ parameter. For the $I_{c}=4-27$ A the slight difference between the values of the parameters $S t$ and $S z$ indicates the negligible

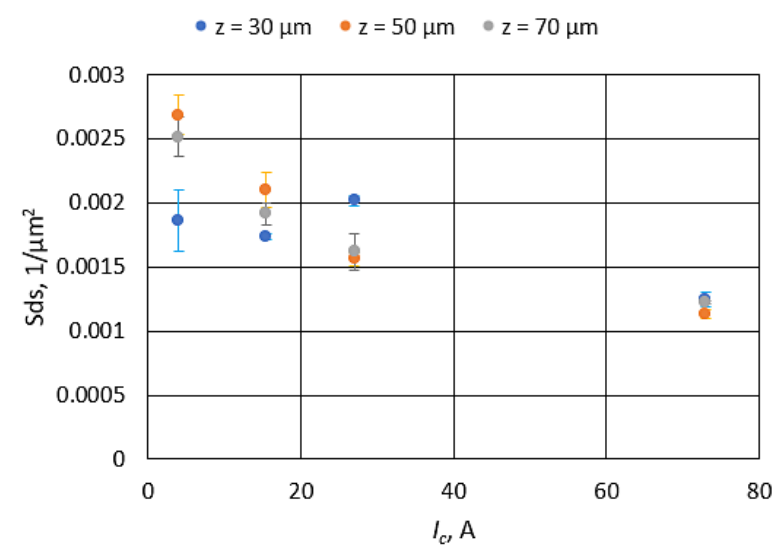

Fig. 11. Summit density parameter $S d s$

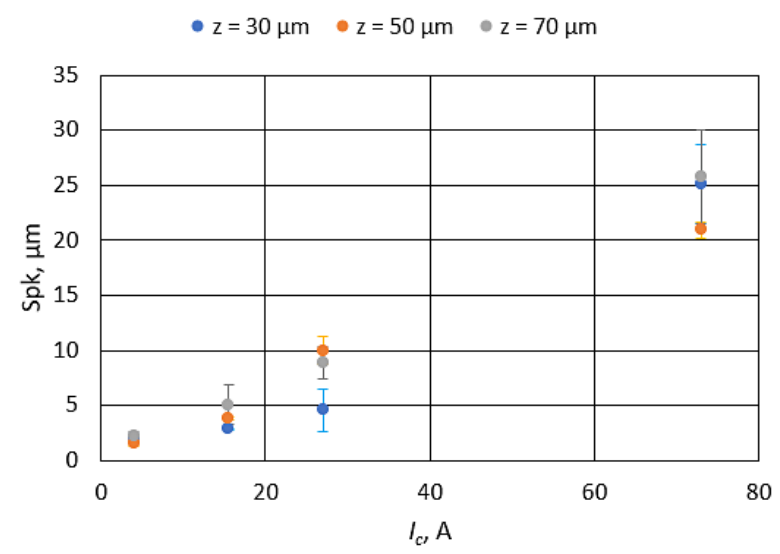

Fig. 12. Reduced peak height parameter $S p k$

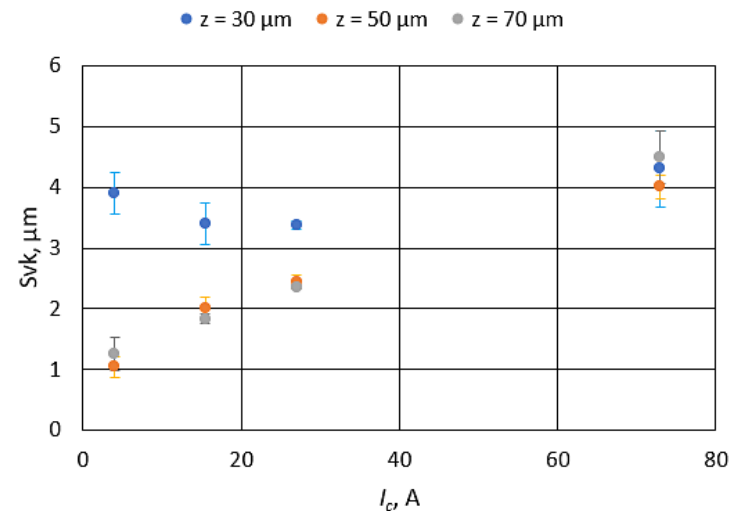

Fig. 13. Reduced valley depth parameter $S v k$

occurrence of random peaks and valleys. This indicates the stability of the discharges during machining. Especially in the case of the infeed $z=50$ $\mu m$, for which the dispersion of the measurements was minimal. For the $I_{c}=73 \mathrm{~A}$, the difference between the $S p$ and $S z$ was significant, which indicates the increase in perturbations reducing the stability of the machining.

The maximum pit height $\mathrm{Sv}$ parameter is presented in Figure 10. The highest values of the 


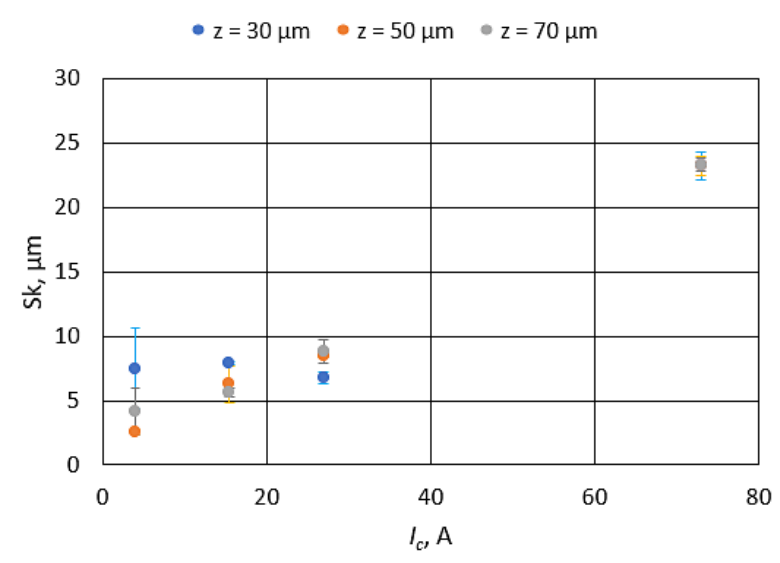

Fig. 14. Core height parameter $S k$

$S v$ parameter were recorded for the infeed $z=$ $30 \mu \mathrm{m}$. This can be the result of the machining marks remaining after roughing machining. As a rule, the lowest values were obtained for the infeed $z=50 \mu \mathrm{m}$. For the highest value of the peak current $I_{c}=73 \mathrm{~A}$, the maximum pit height is of a similar value $S v=25 \mu \mathrm{m}$.

The summit density $S d s$ (Fig. 11) decreases with the increase of the peak current $I$. One can observe that with the lower values of the parameter $I_{c}=4 \mathrm{~A}$ and $I_{c}=15.5 \mathrm{~A}$, the lowest summit density $S d s$ was achieved for the infeed $z=30$ $\mu \mathrm{m}$, and the highest for the infeed $z=50 \mu \mathrm{m}$. With the increase of the peak current, the distribution of the $S d s$ parameter values for both infeeds was the opposite. For the highest values of the peak current $I_{c}=73 \mathrm{~A}$, the $S d s$ parameter assumed a similar value $S d s=0.0012 \mathrm{pks} / \mathrm{mm}^{2}$.

The reduced peak height $S p k$ parameter (Fig. 12) proves to be useful in the assessment of abrasion resistance. The distribution of Spk parameter is correlated with the distribution of the $S p$ parameter. With the increase of the peak current $I_{c}$, the value of the $S p k$ parameter increased. The lowest measurement dispersion was obtained for the infeed $z=50 \mu \mathrm{m}$.

The reduced valley depth $S v k$ can be used in the assessment of the ability to hold lubricating fluid (Fig. 13).

For the infeeds $z=50 \mu m$ and $z=70 \mu m$ the value of the $S v k$ parameter increases similarly. For the infeed $z=30 \mu m$, the $S v k$ parameter reaches high values with the lowest $I_{c}$ values. For the $I_{c}=$ $73 \mathrm{~A}$, the value of the $S v k$ parameter is similar for all tested infeeds.

The core height $S k$ parameter is presented in Figure 14. It allows to describe the nominal roughness (peak to valley). The greatest differences for individual infeeds were recorded at the

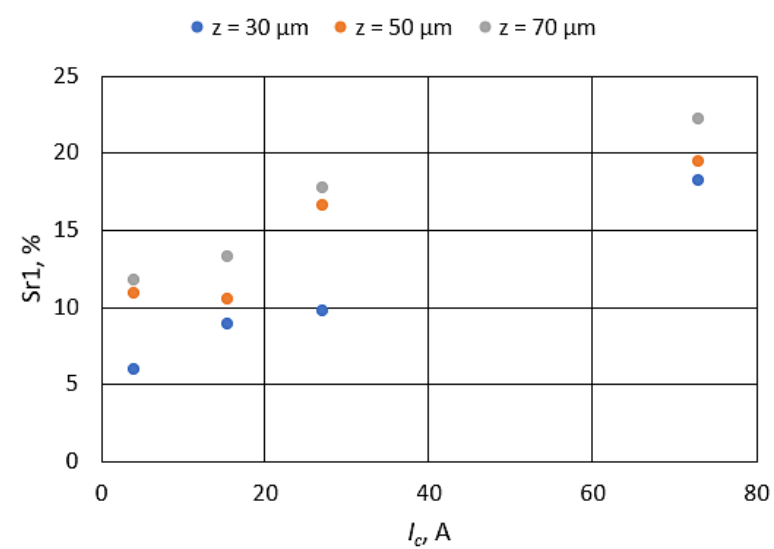

Fig. 15. Upper bearing surface $S r l$

lowest value of the peak current $I_{c}=4$ A. With the increase of the $I_{c}$ parameter, the difference in the Sk roughness value between the tested infeeds decreased. For the highest value of $I_{c}=73 \mathrm{~A}$, almost the same $S k$ roughness value was recorded.

The upper bearing surface $\mathrm{Srl}$ is presented in Figure 15. With the increase of the peak current $I_{c}$ and the infeed $z$, the upper bearing surface $S r l$ increases.

The lower bearing surface $S r 2$ (Fig. 16) is strongly correlated with the distribution of the Srl parameter. However, one can observe a significant increase in the lower bearing surface for the infeed $z=50 \mu \mathrm{m}$ and the peak current $I_{c}=73$ A in comparison with the $S r l$ parameter.

Figure 17 presents selected parameters of the surface roughness after tests conducted with $I_{c}=$ $4 \mathrm{~A}$ and the infeed $z=30 \mu \mathrm{m}$ and $z=50 \mu \mathrm{m}$. In addition to the higher $S a$ and $R a$ parameters for the sample machined with the infeed $z=30 \mu \mathrm{m}$, similar values of the parameters $S p$ for both infeeds can be noticed, but at the same time a significantly higher $S v$ parameter for the infeed $z=$ $30 \mu \mathrm{m}$ can be observed, which indicates that only

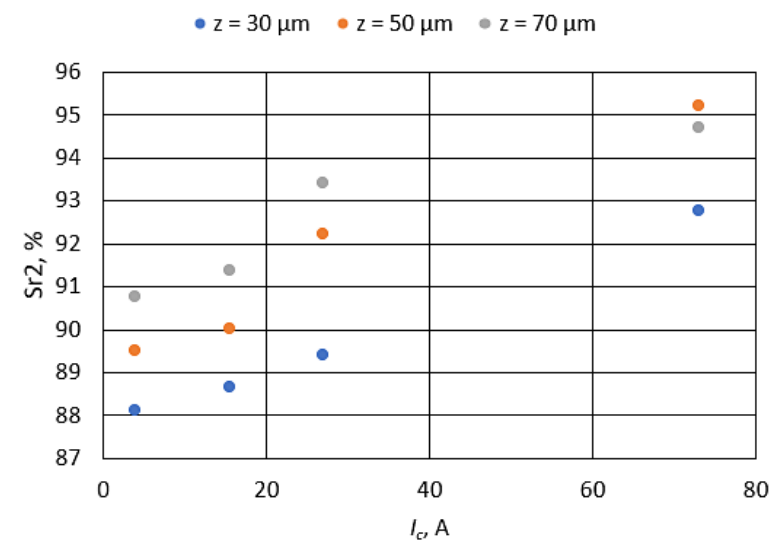

Fig. 16. Lower bearing surface $S r 2$ 
the peaks were removed in the case of this sample. The negative value of the Ssk parameter for the infeed $z=30 \mu \mathrm{m}$ also indicates the removal of only the peaks left after roughing machining.
Figure 18 presents the surface topography of the sample with the lowest surface roughness $\operatorname{Ra}\left(I_{c}=4 \mathrm{~A}, z=50 \mu \mathrm{m}\right)$, and Figure 19 with the highest surface roughness $R a\left(I_{c}=73\right.$

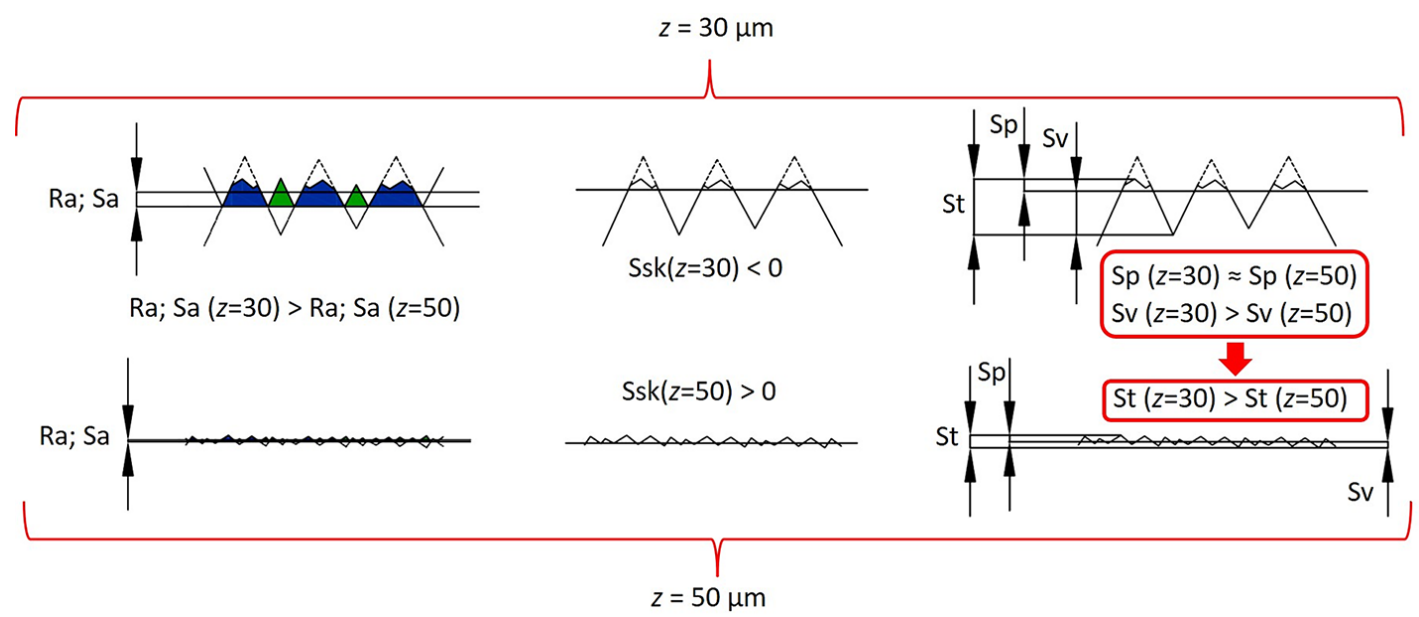

Fig. 17. Comparison of selected surface roughness parameters for tests with $I_{c}=4 \mathrm{~A}$ and infeed $z=30 \mu \mathrm{m}$ and $z=50 \mu \mathrm{m}$

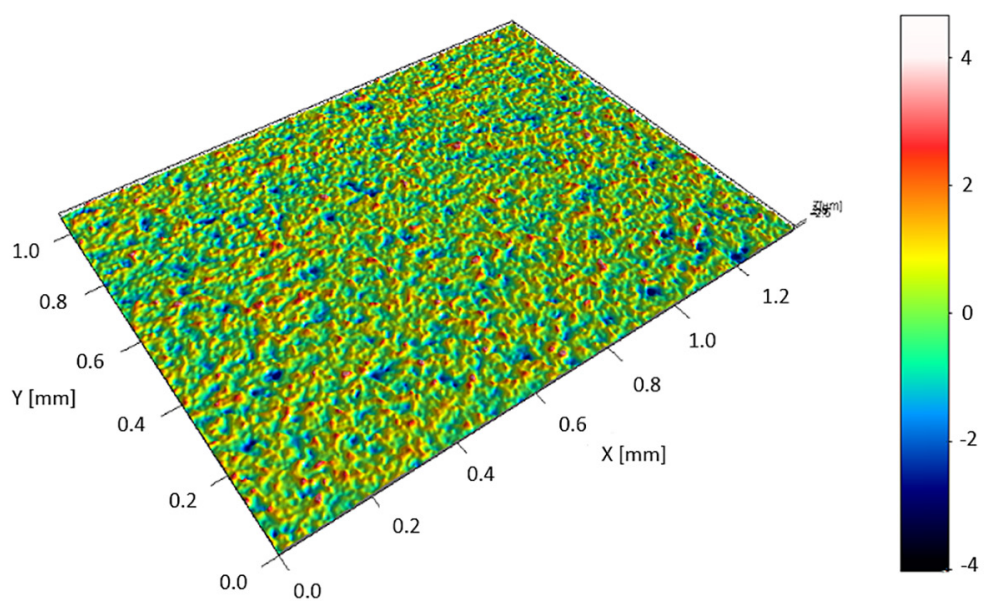

Fig. 18. Surface topography of the sample with the lowest surface roughness parameter Ra (isometric view)

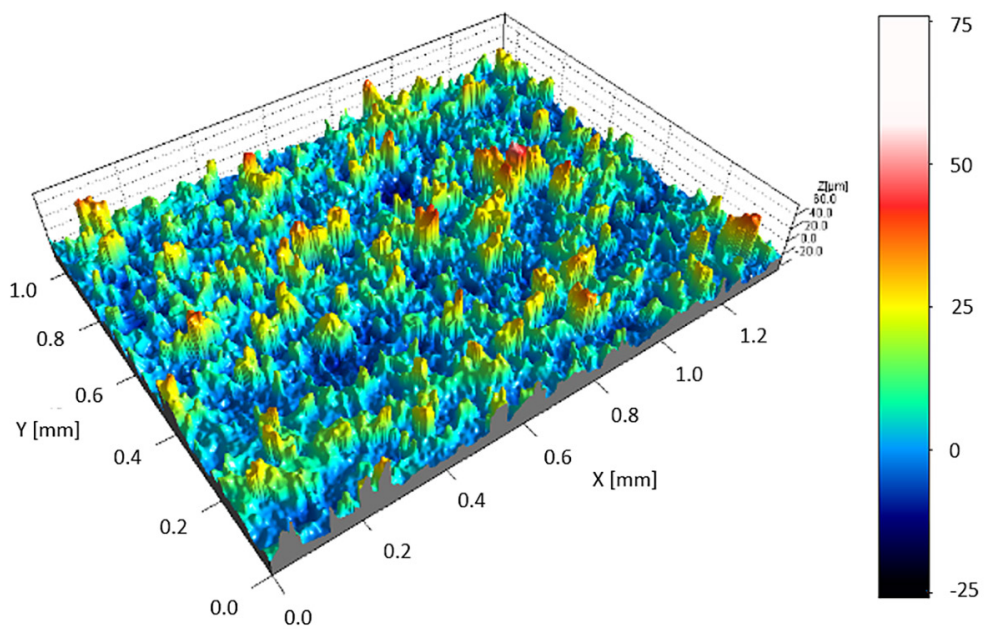

Fig. 19. Surface topography of the sample with the highest surface roughness parameter Ra (isometric view) 
A, $z=70 \mu \mathrm{m}$ ). Both topographies are random. No visible scratches or ridges can be discerned. Both surfaces are characterized by an even distribution of peaks and valleys. Oniszczuk et al. [37] also noted that individual surface texture parameters are dependent on the discharge energy. The authors conclude, on the basis of surface topography, that the highest values of the
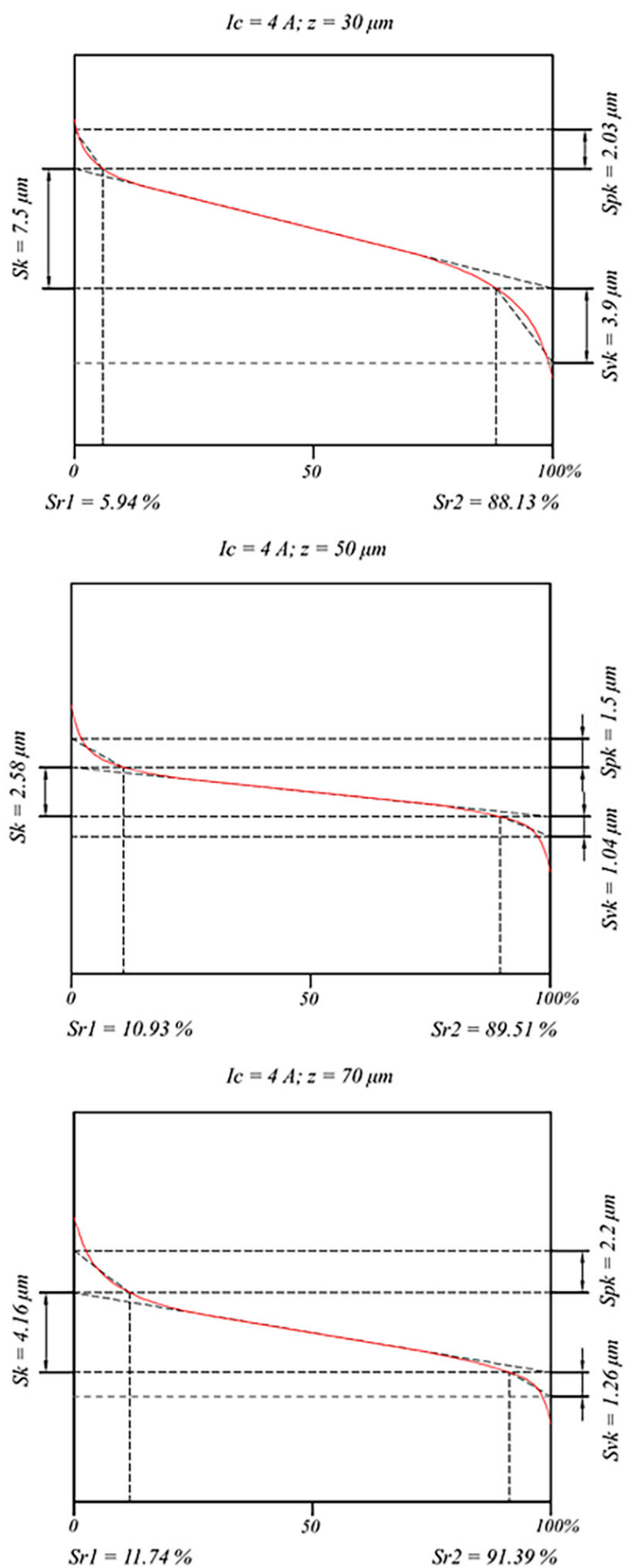

discharge energy significantly increase the vertical surface parameters. It increases the size of the surface craters and the distance between them as well.

Figure 20 presents the bearing area curves for the tests conducted with all the infeeds $z$, as well as the lowest peak current $I_{c}=4 \mathrm{~A}$ and the highest peak current $I_{c}=73 \mathrm{~A}$.
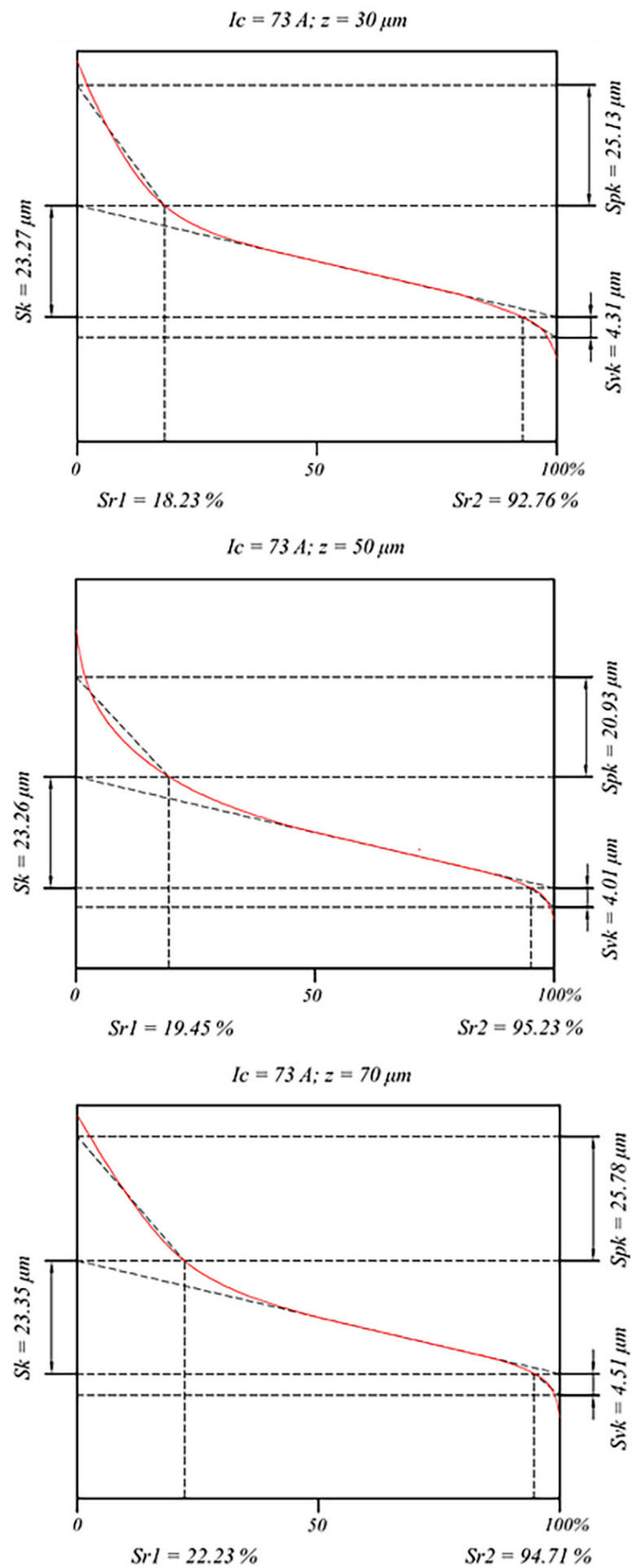

Fig. 20. Abbott - Firestone curves for the selected samples 
One can observe a significant influence of the peak current $I_{c}$ on the bearing area curve. The impact of the infeed $z$ is much lower. For the $I_{c}=73 \mathrm{~A}$, the upper bearing surface $S r l$ increased significantly in comparison with the tests conducted at $I_{c}=4 \mathrm{~A}$. The lower bearing surface $S r 2$ of the samples machined at $I_{c}=73$ A did not increase significantly. For the highest values of the peak current $I_{c}$, the $S p k$ parameter increased approximately 12 times compared to the tests conducted with the lowest $I_{c}$. Surfaces machined with the peak current $I_{c}=4 \mathrm{~A}$ are characterized by much higher abrasion resistance than surfaces machined with the highest $I_{c}$ parameter value. The $S k$ parameter increased by 3 to 9 times. On the other hand, the increase in the $S v k$ parameter, and thus the surface ability to hold lubricating fluids, was up to 3.5 times. It can be seen that for the peak current $I_{c}=73$ A, the values of the $S p k, S k$ and $S v k$ parameters are similar for all infeed values. In the case of the sample machined with $I c=4 \mathrm{~A}$ and $z=30$ $\mu m$ only the value of the Spk parameter is similar for all the feeds. The values of the $S k$ and Svk parameters increased approximately three times. This indicates incomplete removal of the unevenness after roughing machining. Oniszczuk et al. arrived at similar conclusions [37]. The value of the roughness peaks $S p k$ is lower for lowest energy of discharge. Low discharge energy makes the surface able to provide better lubrication and more resistant to abrasion compared to the surface obtained with higher discharge energy.

Figure 21 presents a general diagram describing the influence of the tested peak current and infeed parameters on the surface roughness after finishing WEDM. The increase in peak current has almost linear impact on the increase in surface roughness. In case of the infeed, low values result in removing of only peaks of unevenness left from roughing machining. Too high a value results in breaking the electrode. There is a range between these values, in which the optimal infeed can be determined at low peak current values. In the presented experimental tests, the lowest $\mathrm{Ra} / \mathrm{Sa}$ surface roughness was achieved for the infeed $z=50 \mu \mathrm{m}$ and $I_{c}=4 \mathrm{~A}$. This sample was chosen to measure the white layer and the hardness of the surface layer in comparison with the sample with the highest $R a$ / $\mathrm{Sa}$ surface roughness (obtained with an infeed of $z=70 \mu m$ and $\left.I_{c}=73 \mathrm{~A}\right)$.

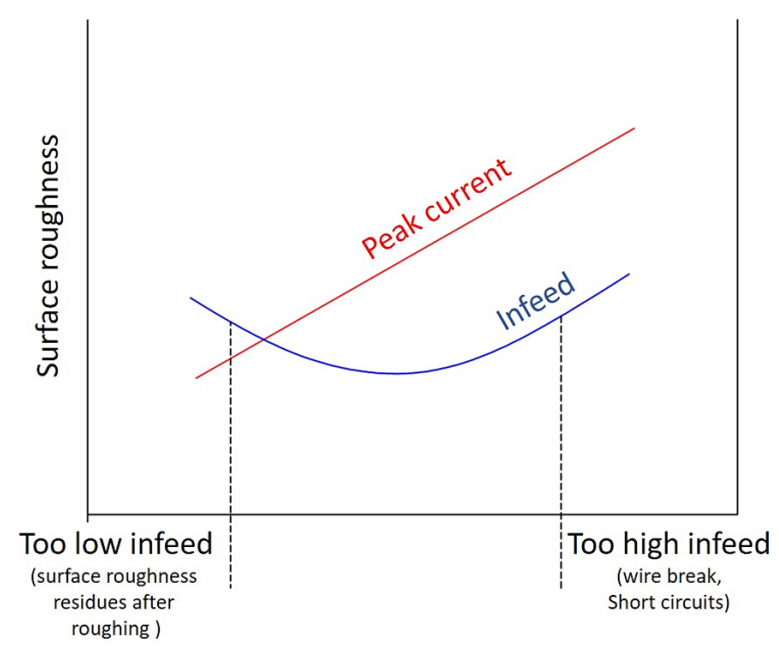

Fig. 21. The variations in the influence of the peak current and infeed on the surface roughness

\section{Surface layer}

Figure 22 presents the surface layer and the thickness of the white layer (recast layer) for the sample with the lowest surface roughness $R a$ (a) and the sample with the highest roughness $R a$ (b). For low values of the $I_{c}$ parameter and the infeed $z$ from the middle of the tested range, the obtained white layer thickness was in the range of $3-5 \mu \mathrm{m}$. The layer was compact and evenly distributed over the entire surface. For the highest $I_{c}$ and $z$ values, the layer was irregular. Higher machining parameters resulted in disturbances in the erosion of the material and in the dielectric flow. This resulted in the irregular deposition of the eroded material, which in turn led to an increase in the thickness of the layer to approximately 11-13 $\mu \mathrm{m}$, and occasionally even above $15 \mu \mathrm{m}$. Sharma et al. [29] observed a lower white layer
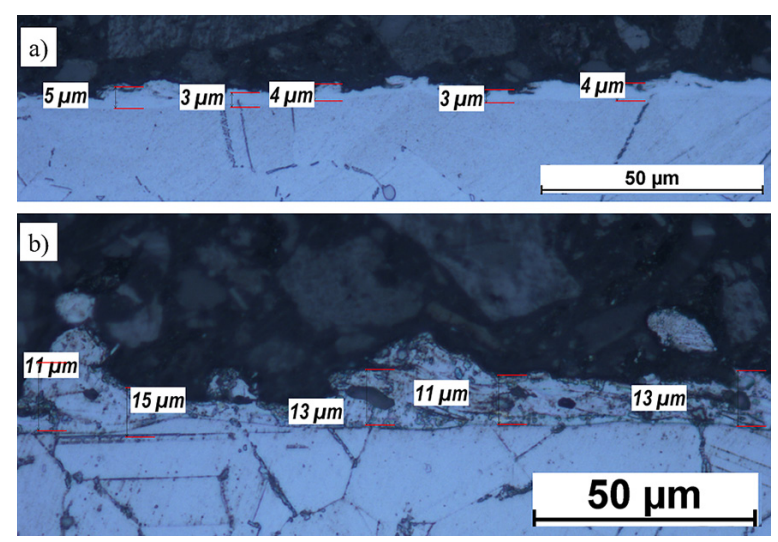

Fig. 22. Surface layer: a) sample machined with $\left.I_{c}=4 \mathrm{~A}, z=50 \mu \mathrm{m}, \mathrm{b}\right)$ sample machined with $\mathrm{I}_{c}=73 \mathrm{~A}, z=70 \mu \mathrm{m}$ 
formation tendency with lower discharge energy values $(0.0353 \mathrm{~J})$. With the increase in the discharge energy $(0.0386 \mathrm{~J})$, the significant increase in the thickness of the white layer can be noticed.

\section{Hardness}

Due to the thickness of the white layer of a few micrometers, the measurement of nanohardness was implemented in order to properly measure the hardness in the surface layer. As before, for the hardness tests, the samples with the lowest (Fig. 23a) and the highest (Fig. 23b) surface roughness $R a$ were chosen. On the abscissa, the value of $0 \mu m$ represents the surface of the bulk workpiece. On the left side there is a measurement of the hardness of the white layer at a distance of $2.5 \mu \mathrm{m}$ from the bulk workpiece. On the right side from the value of $0 \mu m$ there are measurements of the hardness of the workpiece bulk at a depth of 5-35 $\mu \mathrm{m}$ in $10 \mu \mathrm{m}$ increments.

The hardness of the white layer for both samples is significantly lower than that of a workpiece bulk. One can observe significant dispersion of hardness measurements, which possibly resulted from different origin of the material of the surface layer, which consists of the eroded material of the workpiece and the electrode, as well as from their mixing when they solidified again on the machined surface. At successive depths of the bulk workpiece, the hardness stabilizes and the dispersion decreases. In the case of a sample machined with lower parameters, the hardness stabilizes at the first measurement depth $-5 \mu \mathrm{m}$. In the case of higher parameters, the hardness stabilizes at a depth of approximately 25 $\mu m$. The difference result from the higher temperature and the larger heat affected zone. Due to the low carbon content of Inconel 718, there is no hardening in a dielectric and no forming of the hardened layer, which is common in case of steel. Sharma et al. [38] tested the microhardness in the surface layer of the Inconel 718 alloy after roughing and finishing. WEDM machining lowered the microhardness to a depth of about $80 \mu \mathrm{m}$. After roughing, the microhardness in the surface layer was lower by more than $100 \mathrm{HV}$ compared to the bulk material. The finishing machining influenced the microhardness of the surface layer to a much lesser extent. The difference was approximately $35 \mathrm{HV}$.

Based on the presented results of the surface roughness, white layer and hardness of the white layer, the interaction of the peak current and infeed in relation to the surface quality after finishing WEDM is presented (Fig. 24). With low peak current values, the role of the infeed in achieving a high surface quality increases. As the peak current increases, the influence of the infeed on the surface quality decreases.

a)

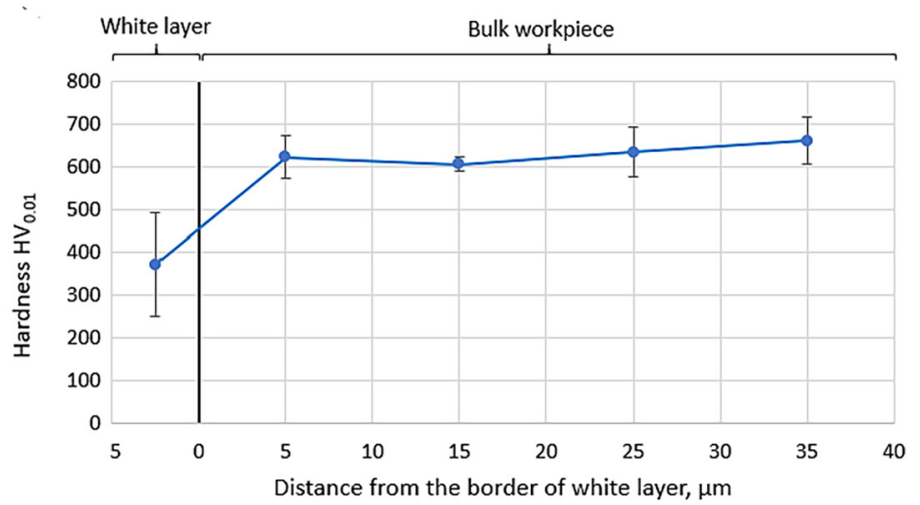

b)

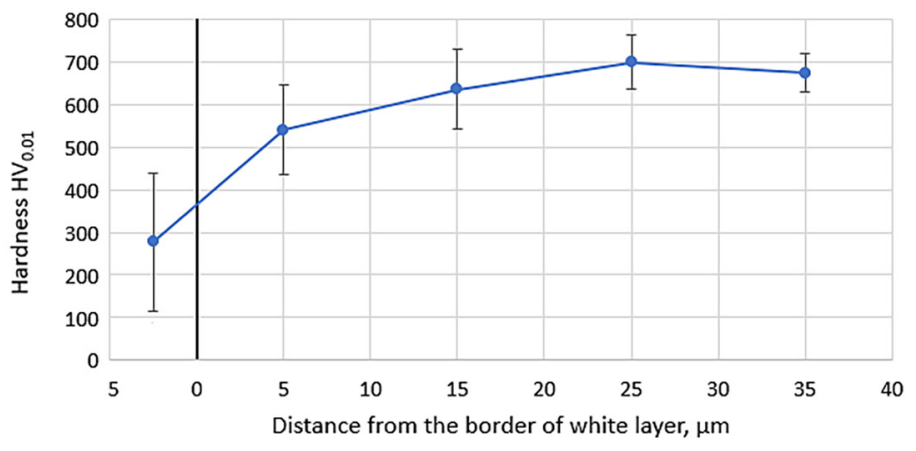

Fig. 23. Hardness $\mathrm{HV}_{0.01}$ : a) sample machined with $I_{c}=4 \mathrm{~A}, z=50 \mu \mathrm{m}$, b) sample machined with $I_{c}=73 \mathrm{~A}, z=70 \mu \mathrm{m}$ 


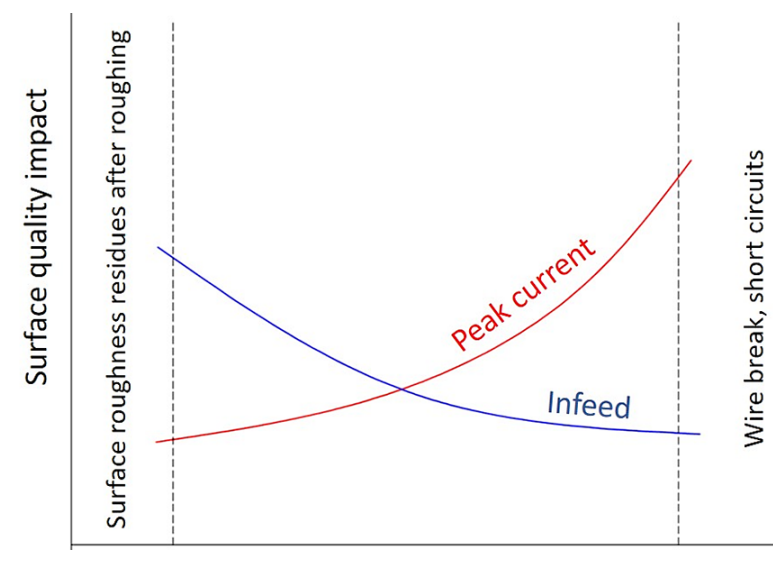

Fig. 24. Influence of the peak current and infeed on the surface quality after finishing WEDM

\section{CONCLUSIONS}

The surface of the workpiece after WEDM is the result of the overlapping craters caused by electrical discharges. The size of these craters depends on the electrical parameters of the machining. Analyzing the influence of set parameters, the infeed $z$ has a significant influence on values of the surface topography parameters at low values of the peak current $I$. For higher values of the peak current $I_{c}$, the influence of the infeed $z$ decreases. Due to the surface interaction, the best surface topography parameters were achieved for the peak current equal to or less than $I_{c}=15.5 \mathrm{~A}$ as well as the infeed from the middle of the tested range $z=50 \mu \mathrm{m}$. The too low value of the infeed $z$ resulted in incomplete removal of machining marks after roughing at low values of the peak current $I_{c}$. The highest peak current value $I_{c}=73 \mathrm{~A}$ allowed to completely remove the machining marks after roughing, even at the lowest infeed $z=30 \mu \mathrm{m}$, while simultaneously significantly increasing surface roughness parameters. However, for the higher $I_{c} \mathrm{pa}-$ rameters, the stability of the machining decreased. Lower values of the $I_{c}$ parameters reduced thickness of the white layer by about $65 \%$. No microcracks penetrating into bulk workpiece were registered in any of the samples. Highest values of the $I_{c}$ parameter reduced the hardness in the surface layer up to 5 $\mu \mathrm{m}$ into the bulk workpiece. The heat affected zone ranged from approximately $5 \mu \mathrm{m}$ (lowest $I_{c}$ value) to approximately $25 \mu \mathrm{m}$ (highest $I_{c}$ value). The interaction chart between the peak current and infeed was proposed, which can be used in the design of the WEDM finishing technology as a guideline for selecting the parameters according to the required surface quality of the Inconel 718 alloy. Further research should focus on monitoring the surface layer condition mainly in terms of residual stresses.

\section{Acknowledgements}

This work was financed from the funds of the Ministry of Education and Science by Agreement No. DNK/SP/513880/2021 of 22 December 2021, the project " $14^{\text {th }}$ School of Machining and the $43^{\text {rd }}$ Scientific School of Abrasive Machining", under the programme "Perfect Science".

\section{REFERENCES}

1. Rozenek M. Wire electrical discharge machining of aluminium alloy with high copper content. AIP Conference Proceedings. 2018; 020028: 1-11.

2. Płodzień M., Tymczyszyn J., Habrat W., Kręcichwost P. Analysis of EDM Drilling of Small Diameter Holes. In Industrial Measurements in Machining. Springer, Cham, Switzerland. 2020; 1-8.

3. Dąbrowski L., Marciniak M., Oniszczuk-Świercz D. Abrasive blast surface finish after the wire electrical discharge machining (WEDM). Mechanik. 2015; 8-9: 80-83.

4. Świercz R., Oniszczuk-Świercz D. The effects of reduced graphene oxide flakes in the dielectric on electrical discharge machining. Nanomaterials. 2019; 9(3): 1-16.

5. Chaudhari R., Vora J.J., Patel V., Lopez de Lacalle L.N., Parikh D.M. Surface Analyssis of wire-electrical-discharge-machining-processed shape-memory alloys. Materials. 2020; 13(3): 1-13.

6. Huang J.T., Liao Y.S., Hsue W.J. Determination of finish-cutting operation number and machining- parameters setting in wire electrical discharge machining. Journal of Materials Processing Technology. 1999; 87(1-3): 69-81.

7. Świercz R., Oniszczuk-Świercz D., Chmielewski T. Multi-Response Optimization of Electrical Discharge Machining Using the Desirability Function. Micromachines. 2019; 10(1): 1-25.

8. Burek J., Buk J., Płodzień M., Sałata M. Automatic programming of 4-axis Wire EDM CNC machine supported by dedicated programming module. Mechanik. 2016; 3: 216-217.

9. Klocke F., Welling D., Dieckmann J., Veselovac D., Perez R. Developments in wire-EDM for the manufacturing of fir tree slots in turbine discs made of Inconel 718. Key Engineering Materials. 2012; 504-506: 1177-1182.

10. Burek J., Babiarz R., Buk J., Sułkowicz P., Krupa K. The accuracy of finishing WEDM of Inconel 718 turbine disc fir tree slots. Materials. 2021; 14(3): 1-19.

11. Liao Y.S., Huang J.T., Chen Y.H. A study to achieve a fine surface in Wire-EDM. Journal of Materials Processing Technology. 2004; 149(1-3): 165-171.

12. Newton T.R., Melkote S.N., Watkins T.R., Trejo R.M. Investigation of the effect of process param- 
eters on the formation and characteristics of recast layer in wire-EDM of Inconel 718. Materials Science and Engineering: A. 2009; 513-514: 208-215.

13. Aspinwall D.K., Soo S.L., Berrisford A.E., Walder G. Workpiece surface roughness and integrity after WEDM of Ti-6Al-4V and Inconel 718 using minimum damage generator technology. CIRP Annals Manufacturing Technology. 2008; 57(1): 187-190.

14. Li L., Guo Y.B., Wei X.T., Li W. Surface integrity characteristics in wire-EDM of Inconel 718 at different discharge energy. Procedia CIRP. 2013; 6: 220-225.

15. Hasçalýk A., Çaydaş U. Experimental study of wire electrical discharge machining of AISI D5 tool steel. Journal of Materials Processing Technology. 2004; 148: 362-367.

16. Han F., Jiang J., Yu D. Influence of discharge current on machined surfaces by ther-mos-analisys in cut of WEDM. International Journal of Machine Tools \& Manufacture. 2007; 47: 1187-1196.

17. Huang Y., Ming W., Guo J., Zhang Z., Liu G., Li M., Zhang G. Optimization of cutting conditions of YG15 on rough and finish cutting in WEDM based on statistical analyses. Int. J. Adv. Manuf. Technol. 2013; 69: 993-1008.

18. Klocke F., Welling D., Klink A., Perez R. Quality assessment through in-process monitoring of wireEDM for fir tree slot production. Procedia CIRP. 2014; 24: 97-102.

19. Li L., Li Z. Y., Wei X. T., Cheng X. Machining charecteristics of Inconel 718 by Sinking-EDM and Wire-EDM. Materials and Manufacturing Processes. 2015; 30: 968-973.

20. Okada A., Yamauchi T., Higashi M., Nakazawa M., Shimizu T., Uno Y. Effects of wire Surface roughness on Wire EDM characteristics. International Journal of Electrical Machining. 2011; 16: 1-7.

21. Antar M.T., Soo S.L., Aspinwall D.K., Cuttel M., Perez R., Winn A.J. WEDM of aerospace alloys using 'clean cut' generator technology. Proceedings of the 16th International Symposium on Electromachining ISEM. 2010; 285-290.

22. Antar M.T., Soo S.L., Aspinwall D.K., Jones D., Perez R. Productivity and workpiece surface integrity when WEDM aerospace alloys using coated wires. Procedia Engineering. 2011; 19: 2-8.

23. Ayesta I., Izquierdo B., Flaño O., Sánchez J. S., Albizuri J., Avilés R. Influence of the WEDM process on the fatigue behavior of Inconel ${ }^{\circledR} 718$. International Journal of Fatigue. 2016; 92: 220-233.

24. Newton T.R., Melkote S.N., Watkins T.R., Trejo R.M. Investigation of the effect of process parameters on the formation and characteristics of recast layer in wire-EDM of Inconel 718. Materials Science and Engineering: A. 2009; 513-514: 208-215.

25. Scott D., Boyina S., Rajurkar K. P. Analysis and optimization of parameter combinations in wire electrical discharge machining. Int. J. Prod. Res.
1991; 29(11): 2189-2207.

26. Arshad R., Mehmood S., Shah M., Imran M., Qayyum F. Effect of Distilled Water and Kerosene as Dielectrics on Machining Rate and Surface Morphology of Al-6061 During Electric Discharge Machining. Advances in Science and Technology Research Journal. 2019; 13(3): 162-169.

27. Imran M., Shah S.M.R., Mehmood S., Arshad R. Edm of aluminum alloy 6061 using graphite electrode using paraffin oil and distilled water as dielectric medium. Advances in Science and Technology Research Journal. 2017; 11(3): 72-79.

28. Sharma P., Chakradhar D., Narendranath S. Evaluation of WEDM performance characteristics of Inconel 706 for turbine disk application. Materials and Design. 2015; 88: 558-566.

29. Sharma P., Chakradhar D., Narendranath S. Effect of wire material on productivity and surface integrity of WEDM-processed Inconel 706 for aircraft application. JMEPEG. 2016; 25: 3672-3681.

30. Godzimirski J. Nowe technologie lotniczych silników turbinowych. Prace Instytutu Lotnictwa. 2011; 4(213): 22-36.

31. Zalecki W., Łapczyński Z., Rońda J., Gnot A. High temperature properties of Inconel 625 and Inconel 718 alloys. Prace IMŻ. 2013; 3: 35-41.

32. Li L., Li Z. Y., Wei X. T., Cheng X. Machining characteristics of Inconel 718 by Sinking-EDM and Wire-EDM. Materials and Manufacturing Processes. 2015; 30(8): 968-973.

33. Dul I. Application and processing of nickel alloys in the aircraft industry. Przegląd Spawalnictwa. 2009; 81(7-8): 67-71.

34. Burek J., Babiarz R., Płodzień M., Buk J. The influence of electrode infeed in finishing wire electrical discharge machining process on disks fir tree slot accuracy. Mechanik. 2018; 10: 915-917.

35. Huang J.T., Liao Y.S., Hsue W.J. Determination of finish-cutting operation number and machining parameters setting in wire electrical discharge machining. Journal of Materials Processing Technology. 1999; 87: 69-81.

36. Ishfaq K., Mufti N. A., Jawad M., Sajid M., Jahanzai M. Analysis of the effect of wire electric dischage machining process parameters on the formation of high speed steel form tool. Advances in Science and Technology Research Journal. 2018; 12(1): 89-98.

37. Oniszczuk-Świercz D., Świercz R., Nowicki R., Kopytkowski A., Dąbrowski L. Investigation of the influence of process parameters of wire electrical discharge machining using coated brass on the Surface roughness of Inconel 718. AIP Conference Proceedings. 2018; 1-6.

38. Sharma P., Tripathy A., Sahoo N. Evaluation of surface integrity of WEDM processed Inconel 718 for jet engine application. IOP Conf. Series: Materials Science and Engineering 323, Dubai, UAE 2018; 012019. 